INVESTIGATIONS OF Mn(pyr)(aq) ${ }^{+2}$ AND PYRIDINE INTERCALATED $\mathrm{Cd}_{2} \mathrm{P}_{2} \mathrm{~S}_{6}$ LATTICES: MECHANISM OF INTERCALATION AND PERTURBATION OF THE HOST LATTICE.

\title{
E. LIFSHITZ
}

Department of Chemistry, Technion, Haifa 32000 (Israe1)

A.H. FRANCIS

Department of Chemistry, The University of Michigan, Ann Arbor (U.S.A.)

\section{ABSTRACT}

The lamellar transition metal Chalocogeno-Phosphates $\left(\mathrm{M}_{2} \mathrm{P}_{2} \mathrm{~S}_{6}\right)$ form an important family of two-dimensional semiconducting materials. The lamellar structure is formed by stacking $\mathrm{S}-\mathrm{M}_{2 / 3}-(\mathrm{P}-\mathrm{P})_{1 / 3} \mathrm{~S}$ units along a unique crystallographic axis. Under appropriate conditions, guest species can enter the space between the layers to form intercalation compounds. Two main mechanisms are presently proposed for the intercalation reaction: electron transfer from guest to host lattice and cation exchange between cationic intercalated species and lattice metal ions. Both mechanisms create structural and electronic perturbations which often result in a dramatic modification of the chemical and physical properties of the host lattice.

This paper describes the experimental evidence for the mechanisms of intercalation and creation of perturbation in the host lattices. Electron Spin Resonance spectroscopy has revealed cation migration between inter- and intralamellar cationic sites, supporting the cation exchange mechanism for the intercalation of solvated cationic species. Photoluminescence studies of Lewis base molecules intercalated into $\mathrm{M}_{2} \mathrm{P}_{2} \mathrm{~S}_{6}$ have shown a broadening of the conduction band due to the insertion of defects level near the band edges. Complementary measurements utilizing Optically detected Magnetic Resonance Spectroscopy demonstrated the presence of a strongly coupled donor-acceptor pair created upon intercalation via charge transfer mechanism.

\section{INTRODUCTION}

The semiconducting Transition Metal Chalcogeno Phosphates $\left(\mathrm{M}_{2} \mathrm{P}_{2} \mathrm{~S}_{6}\right)$ crystallize in a layer structure and exhibit unusual two-dimensional physical properties $[1,2]$ 
The layers consist of sheets of metals (M) and phosphor pairs (P-P) (in the ratio $2: 1$ ) covalent $1 y$ bonded between $S$ atom planes to form the sequence $\mathrm{S}-\mathrm{M}_{2 / 3}-(\mathrm{P}-\mathrm{P})_{1 / 3}-\mathrm{S}$. The macroscopic structure is formed by stacking the layers along a particular crystallographic axis where the interaction between them are weak van der Waals (VDW) forces. Because of these weak interactions guest molecules (intercalants) can penetrate into the VDW region to form "intercalation" compounds.

In the following paragraphs we describe the investigation of pyridine (pyr) and $\mathrm{Mn}(\mathrm{pyr})(\mathrm{aq})^{+2}$ intercalated $\mathrm{Cd}_{2} \mathrm{P}_{2} \mathrm{~S}_{6}$ compounds, emphasizing the investigation of mechanism of interaction and perturbations in the host lattice created upon intercalation. Several spectroscopic techniques (Electron Spin Resonance, Photoluminescence and Optically Detected Magnetic Resonance) have been utilized. These techniques are sensitive to molecular or atomic scale properties and therefore are suitable for the study of heterogeneous materials like the layered compounds.

\section{RESULTS}

Intercalation induced lattice disorder

Changes in the host lattice crystal structure induced by intercalation were followed by the determination of the changes in the host metals' local coordination. This structure was determined from the Electron Spin Resonance (ESR) spectra of $\mathrm{Mn}^{+2}$ doped single crystals. The $\mathrm{Mn}^{+2}$ impurity in an intralayer position served as a "spin probe" [3].

A representative $X$-band spectrum of $\mathrm{Mn}^{+2}$ impurity in $\operatorname{Cd}_{2} \mathrm{P}_{2} \mathrm{~S}_{6}$ obtained with the external magnetic field parallel to the $C^{\star}$ is shown in figure $1 \mathrm{a}$. The $\mathrm{X}$-band ESR spectrum of pyridine intercalated $\mathrm{Cd}_{2} \mathrm{P}_{2} \mathrm{~S}_{6}(1 \% \mathrm{Mn})$ is substantially different and is shown in figure $1 \mathrm{~b}$. The loss of resolution and broadening indicate existence of structural disorder. In addition the last spectrum is sensitive to temperature and frequency of measurement as shown in the following spectra (Figs. 1c \& 1d). These dependents are evident for additional dynamic perturbation created upon the motional ability of the intercalants in the VDW region. After deintercalation of the pyridine molecules, the spectrum nearly regained its form prior to intercalation (Fig. 1e). A slight residual broadening indicated irreversible disorder in the crystal introduced by the intercalation-deintercalation cycle.

\section{Cation exchange mechanism in the intercalated $\mathrm{Cd}_{2} \mathrm{P}_{2} \mathrm{~S}_{6}$}

The cation exchange mechanism has been discussed in detail for the $\mathrm{M}_{2} \mathrm{P}_{2} \mathrm{X}_{6}$ materials and it has been suggested that the di-positive transition metal ions which are not stabilized by the crystal field (Cd,Zn) are easily 
displaced from the lattice to compensate for charge of the intercalated ions [4-7] We have examined the intercalation of paramagnetic Mn(pyridine/water) ${ }^{+2}$ complexes into $\mathrm{Cd}_{2} \mathrm{P}_{2} \mathrm{~S}_{6}$ lattices. The ESR results (not shown) have indicated that two intercalated complexes $\operatorname{Mn}(\operatorname{pyr})_{n}(a q)^{+2}(n=1,2)$ and $\mathrm{Mn}(\mathrm{aq})^{+2}$ were present in the VDW region after intercalation at ambient temperatures. When the intercalated crystals were heated to higher temperatures the pyridine and water molecules had been deintercalated. Then the ESR spectrum approached that of a $\left(\mathrm{Mn}^{+2}\right)_{\mathrm{ca}}$ center shown in figure 1e. We conclude that substantial amounts of the $\mathrm{Mn}^{+2}$ that entered the VDW region as water/pyridine complexes were transferred to a metal position in the intra-layer space upon thermal deintercalation of the other molecules.

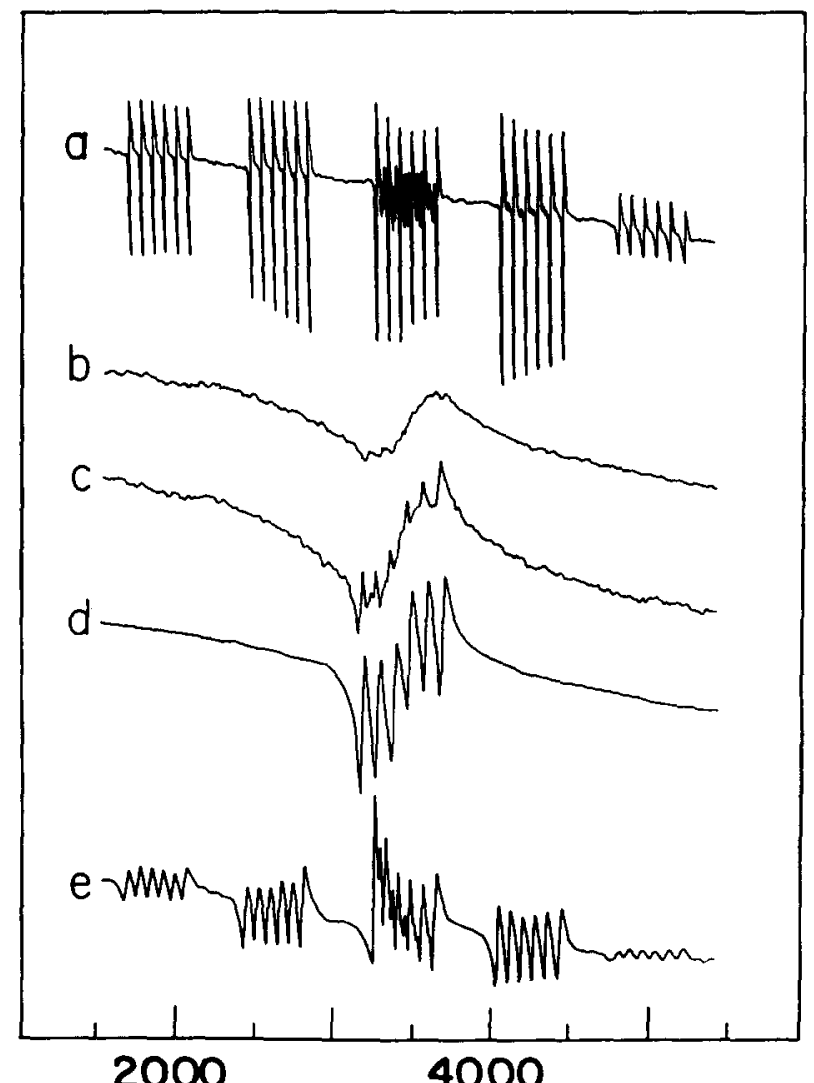

\section{Magnetic field $(H)$ in gauss -}

Fig. 1. ESR spectrum of $\mathrm{Mn}^{+2}$ in $\mathrm{Cd}_{2} \mathrm{P}_{2} \mathrm{~S}_{6}$ : (a) X-band at $\mathrm{T}=298 \mathrm{~K}$, (b) $X$-band, intercalated with pyridine, $T=298 \mathrm{~K}$, (c) $X$-band, intercalated with pyridine, $\mathrm{T}=153 \mathrm{~K}$, (d) Q-band, intercalated with pyridine, $\mathrm{T}=298 \mathrm{~K}$, (e) $\mathrm{X}$-band, intercalated with pyridine or $\mathrm{Mn}^{+2}$ (pyridine/water). 
Electron transfer mechanism and perturbation of the electronic band structure in the intercalated $\mathrm{Cd}_{2} \mathrm{P}_{2} \mathrm{~S}_{6}$ lattices

When Lewis base molecules are intercalated into a $\mathrm{M}_{2} \mathrm{P}_{2} \mathrm{~S}_{6}$ lattices, the process involves electron transfer from intercalants (donor) to the host lattices (acceptors) [8-10]. The present paragraph describes our investigations of the pyridine intercalated compound $\left[\mathrm{Cd}_{2} \mathrm{P}_{2} \mathrm{~S}_{6}\right.$ (donor)]. It was suggested by Schollhorn [11] that the pyridine intercalation is correlated with molecular disproportionation followed by charge transfer according to

$\mathrm{X}_{\text {pyr }} \longrightarrow \mathrm{X} / 2(\mathrm{pyr}-\mathrm{pyr})+\mathrm{XH}^{+}+\mathrm{Xe}^{-}$

$\mathrm{Xpyr}+\mathrm{XH}^{+} \longrightarrow \mathrm{X}\left(\left(\mathrm{pyrH}^{+}\right)\right.$

$\mathrm{Xe}^{-}+\mathrm{Cd}_{2} \mathrm{P}_{2} \mathrm{~S}_{6} \longrightarrow\left(\mathrm{Cd}_{2} \mathrm{P}_{2} \mathrm{~S}_{6}\right)^{\mathrm{x}-}$,

then the charged donor in the ground state $\left(D^{+}\right)$is to be formulated as $\left.\left[(\mathrm{pyr})_{1-2 x}\left(\mathrm{pyrH}^{+}\right)_{x} \text { (pyr-pyr }\right)_{\times / 2}\right]^{\mathbf{x}}$ and the charged acceptor $\left(\mathrm{A}^{-}\right)$as $\left(\mathrm{Cd}_{2} \mathrm{P}_{2} \mathrm{~S}_{6}\right)^{\mathrm{x}-}$. The donor-acceptor $(D-A)$ pairs induce energy levels in the forbidden band gap region as shown schematically in figure 3a. The energies of these leve1s were determined by Photoluminescence (PL) Spectroscopy [12]. The luminescence spectrum of pyridine intercalated $\mathrm{Cd}_{2} \mathrm{P}_{2} \mathrm{~S}_{6}$ is shown in figure 2 and it is associated with recombination luminescence of the D-A pair created upon intercalation.

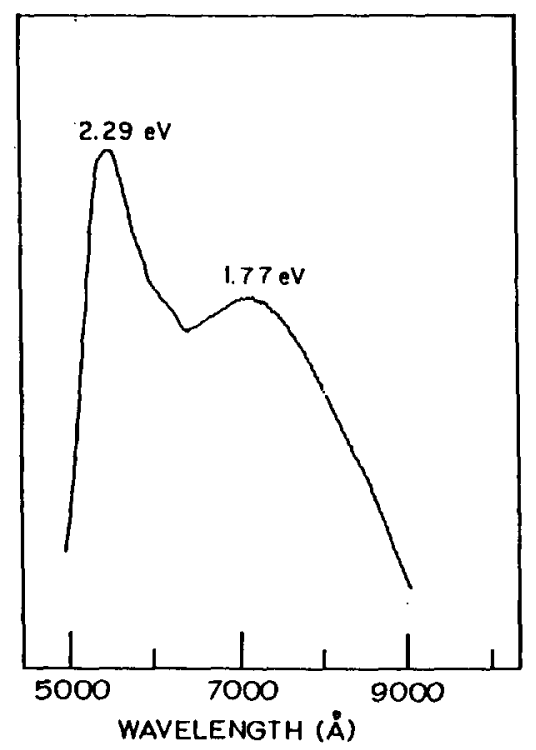

Fig. 2. Photoluminescence emission spectrum of pyridine intercalated $\mathrm{Cd}_{2} \mathrm{P}_{2} \mathrm{~S}_{6}$ lattices. 
The identification of the D-A sites was determined by utilizing Optically Detected Magnetic Resonance (ODMR) spectroscopy. If we assume that the donor and acceptor are weakly coupled and both have spin 1/2 (the spin quantum number of the donor in the excited state refer to an electron and that of the acceptor refer to a hole), they would constitute the four spin levels at the excited state as shown in figure $3 \mathrm{~b}$. Microwave radiation causes magnetic resonance transitions between the spin levels, as indicated by the small arrows in the figure. The singlet states will recombine more readily with the singlet ground state than do the triplet states. When the magnetic resonance of either the donor or acceptors occurs, the excess population in the triplet states is transferred to the strongly emitting states, and the intensity of the emitted light increase. The ODMR spectrum shown in figure 4 is then obtained by monitoring changes of the $D-A$ recombination emission at resonance. The labelled $D$ resonance have shown isotropic behaviour with $g$ value nearly 2.00 , suitable for a guest molecule in a disordered environment in the VDW region. However, the A resonance exhibits unisotropic effects and its $g$ value deviates from 2.00 .

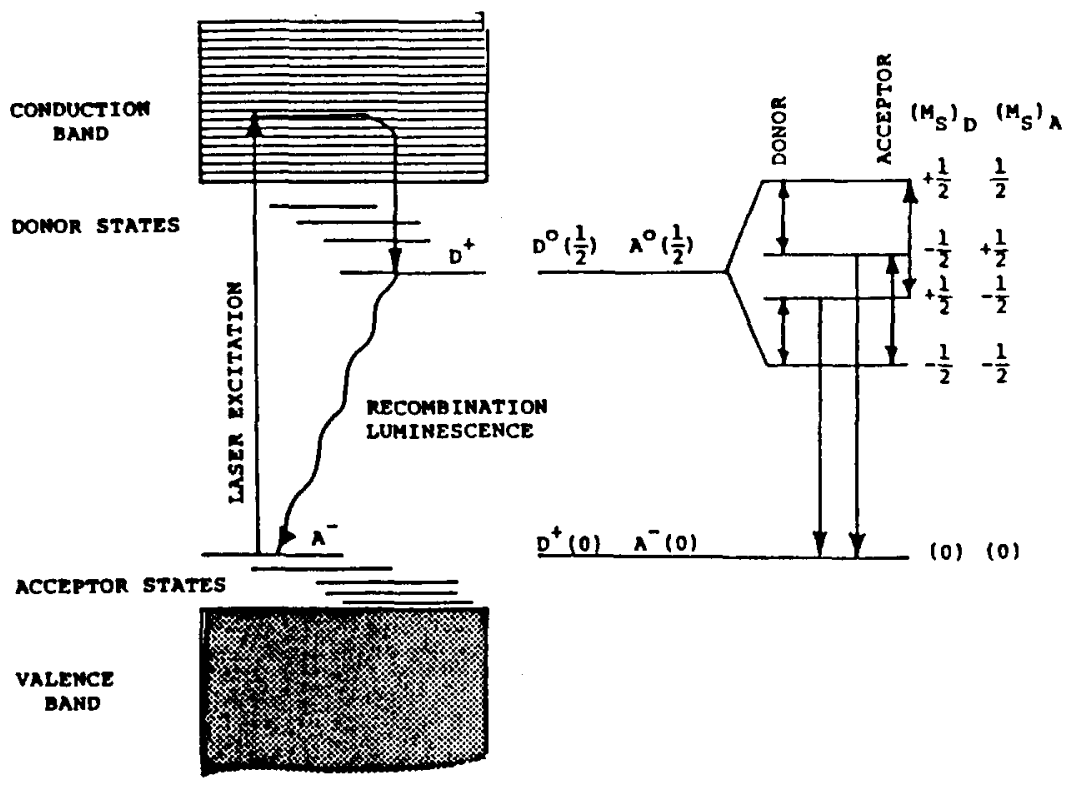

(a)

(b)

Fig. 3. Energy level diagram for Donor-Acceptor pairs in the pyridine intercalated $\mathrm{Cd}_{2} \mathrm{P}_{2} \mathrm{~S}_{6}$ compounds. 
Since the resolution of hyperfine structure of the A resonance was limited, at this point we can only conclude that the donated electron is not mobile in the host layer but rather localized in an intra-layer position. The acceptor site may be either intrinsic ( $\mathrm{P}-\mathrm{P}$ or $\mathrm{S}$ or vacancy) or extrinsic (involving traces of impurities).

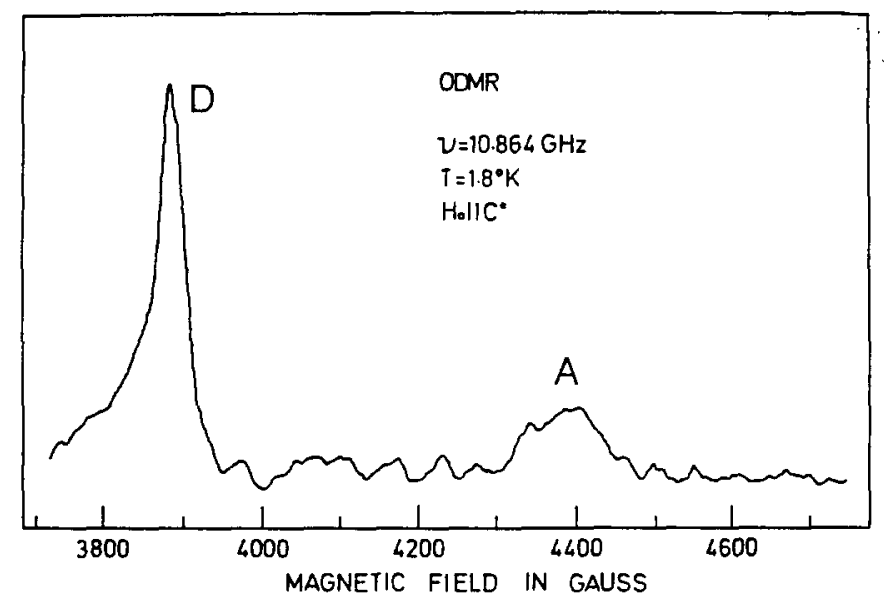

Fig. 4. ODMR spectrum of Donor and Acceptor sites in $\mathrm{Cd}_{2} \mathrm{P}_{2} \mathrm{~S}_{6}$ (pyridine) lattices.

\section{REFERENCES}

1 V.W. Klingen, R. Ott and H. Hahn, Z. Anorg. Allg. Chem., 396 (1973) 21.

2 V.W. Klingen, G. Eulenberger and H. Hahn, Z. Anorg. Allg. Chem., 401 (1973) 97

$3 \mathrm{M}$. Michalowicz and R. Clement, Inorg. Chem., 21 (1982) 3872.

4 E. Lifshitz, A. Gentry and A.H. Francis, J. Phys. Chem., 88 (1984) 3038.

5 R. Bred, G. Ouvrard and J. Rouxe1, Mat. Res. Bull., 20 (1985) 1257.

6 D.A. Cleary, J. Groh, E. Lifshitz, and A.H. Francis, J. Phys. Chem., 92 (1988) 1551.

7 J.P. Audiere, R. Clement, Y. Mathey, and C. Mazières, Physica 99B (1980) 133.

8 Y. Kanzaki, S. Ogura, O. Matsumoto, and Y. Toida, Physica 114B (1982) 399.

9 G.R. Fatseas, M. Evain, G. Ouvrard, R. Brec, and M.H. Whangbo, Phys. Rev. B. 35 (1987) 3082 .

10 J.V. Acrivos and J.R. Salem, Philos. Mag., 30 (1974) 603.

11 R. Schollhorn, Physica 99B (1980) 89.

12 D.A. Cleary, A.H. Francis and E. Lifshitz, J. Lumin., 35 (1986) 163. 